\title{
Effectiveness of monthly and fortnightly anti-VEGF treatments for age-related macular degeneration
}

\author{
Efetividade de tratamentos anti-VEGF mensais e quinzenais para \\ a degeneração macular relacionada à idade
}

Renata Portella Nunes', Flávio Eduardo Hirai', Letícia Fernandes Barroso', Emmerson Badaró1, Eduardo Novais', Eduardo Buchele Rodrigues', Mauricio Maia', Octaviano Magalhães Jr.', Michel Eid Farah'

1. Department of Ophthalmology and Visual Sciences, Escola Paulista de Medicina, Universidade Federal de São Paulo, São Paulo, SP, Brazil.

\begin{abstract}
I Purpose: To study the efficacy and safety of treatments with ranibizumab and bevacizumab for exudative age-related macular degeneration. Methods: A parallel randomized clinical trial was conducted to compare the efficacy and safety of three regimens (bevacizumab every month, bevacizumab every 2 weeks, and ranibizumab every month), followed by as-needed retreatments, for 1 year, in previously untreated individuals with age-related macular degeneration. The primary outcome was change in visual acuity and in central macular thickness after 1 year of follow-up. Subjects were assigned randomly to one of the three groups in a 1:1:1 ratio, and investigators and examiners were blinded to the randomization results. Results: We included 15 patients in each group. After 1 year of follow-up, we found statistically significant improvements in visual acuity and central macular thickness reduction in all groups. However, we found no statistically significant differences between the three groups. Conclusions: The bi-weekly follow-up was effective and we found no significant differences in efficacy or safety between the treatments with ranibizumab and bevacizumab.
\end{abstract}

Keywords: Macular degeneration; Retina; Bevacizumab; Ranibizumab; Clinical trial

RESUMO | Objetivo: Estudar a eficácia e segurança dos tratamentos com ranibizumabe e bevacizumabe para a degeneração macular relacionada à idade exsudativa. Métodos: Ensaio clínico paralelo randomizado foi conduzido para comparar a

Submitted for publication: July 23, 2018

Accepted for publication: September 23, 2018

Funding: This study was supported by CNPq (558868/2009-6), FAPESP (2010/15451-0), and CAPES (BEX1059/12-2).

Disclosure of potential conflicts of interest: Dr. Rodrigues reports grants from Bayer and Allergan. The others authors declare having no conflicts of interest.

Corresponding author: Renata Portella Nunes.

Instituto de Olhos de Florianópolis. Rua Presidente Coutinho, 579/501 - Florianópolis SC - 88015-231 - Brazil - E-mail: reportellanunes@gmail.com

Approved by the following research ethics committee: Universidade Federal de São Paulo (\#0345/10) eficácia e segurança de três regimes (bevacizumabe a cada mês, bevacizumabe a cada 2 semanas e ranibizumabe todos os meses), seguidos por retratamentos conforme necessidade, durante 1 ano, em indivíduos previamente não tratados com degeneração macular relacionada à idade. O desfecho primário foi alteração na acuidade visual e na espessura macular central após um ano de seguimento. Os indivíduos foram designados aleatoriamente para um dos 3 grupos em uma proporção de 1:1:1, e os investigadores e examinadores foram mascarados para os resultados da randomização. Resultados: Foram incluídos 15 pacientes em cada grupo. Após um ano de seguimento, encontramos melhorias estatisticamente significativas na acuidade visual e na redução da espessura macular central em todos os grupos. No entanto, não encontramos diferenças estatisticamente significativas entre os 3 grupos. Conclusões: O seguimento quinzenal foi eficaz e não encontramos diferenças significativas na eficácia ou segurança entre os tratamentos com bevacizumabe e ranibizumabe.

Descritores: Degeneração macular; Retina; Bevacizumabe; Ranibizumabe; Ensaio clínico

\section{INTRODUCTION}

The current gold-standard treatment for exudative age-related macular degeneration (AMD) involves intravitreal injections of anti-vascular endothelial growth factor (VEGF) drugs, such as bevacizumab (Avastin; Genentech, South San Francisco, CA), ranibizumab (Lucentis; Genentech/Roche, South San Francisco, CA), and aflibercept (Eylea; Regeneron, Tarrytown, NY) ${ }^{(1-6)}$.

Ranibizumab is a recombinant humanized monoclonal antibody fragment that binds to and inhibits all biologically active forms of VEGF-A ${ }^{(7)}$. In 2006, it was approved for ophthalmological use by the Food and Drug Administration, based on two large phase 3 clinical trials, known as the "Minimally Classic/Occult Trial of the Anti-VEGF Antibody Ranibizumab in the Treatment of Neovascular 
$A M D$ " and the "Anti-VEGF Antibody Ranibizumab for the Treatment of Predominantly Classic Choroidal Neovascularization in $A M D$ (ANCHOR)" trials. In addition to preventing vision loss, ranibizumab was the first drug to show visual improvements after 1 year of treatment ${ }^{(8)}$.

On the other hand, bevacizumab is a full-length recombinant humanized monoclonal antibody that binds to and inhibits all biologically active forms of VEGF. It was approved in 2004 for the intravenous treatment of metastatic colorectal cancer, but not for ophthalmological use. However, its off-label use has become a common alternative treatment due to its efficacy and safety, in addition to its availability and lower $\cos ^{(9)}$. In 2005, the first case report of intravitreal bevacizumab use was published and the outcome was similar to that achieved with systemic bevacizumab and intravitreal ranibizumab $^{(10)}$. Since its first use, other retrospective and prospective studies have evaluated intravitreal bevacizumab treatments, both monthly and as-needed, with good anatomical and visual results ${ }^{(11-14)}$.

Researchers generated a pharmacokinetic mathematical model to determine if a more frequent dosing of anti-VEGF drugs (ranibizumab, bevacizumab, and aflibercept) could be beneficial ${ }^{(15)}$. They demonstrated a substantial increase in binding affinity with fortnightly injections, but without a significant increase in peak concentration $^{(15)}$. The same researchers also showed two instances of improved treatment outcomes after fortnightly use of anti-VEGF drugs in patients refractory to monthly treatments. No clinical trials have evaluated fortnightly administrations of anti-VEGF drugs. However, according to the above-mentioned results, more frequent dosing for a short period of time may be a good option for patients showing improvement after 2 weeks of treatment, but fluid recurrence after 4 weeks.

The "Comparison of Age-Related Macular Degeneration Treatments Trial (CATT)" and the "Alternative treatments to Inhibit VEGF in Age-related choroidal Neovascularization (IVAN)" studies conducted in the United States and in the United Kingdom, respectively, were pivotal clinical trials comparing bevacizumab and ranibizumab for exudative AMD treatment ${ }^{(16,17)}$. Both studies utilized the same treatment strategy, and both drugs showed equivalence in efficacy and safety after 2 years ${ }^{(16-19)}$. Other smaller clinical studies comparing the two drugs were conducted in the US, Austria, and Switzerland, with similar results ${ }^{(20-22)}$.

Based on the studies published, exudative AMD treatment should probably be individualized for each patient. Prognosis indicators and therapeutic responses to each drug should be considered, in addition to the financial situation, drug availability, and the patient's willingness to undergo repeated injections. In clinical practice, some patients with excellent therapeutic response require few and spaced injections, but those who respond poorly might benefit from more intensive treatments (even with injections every 2 weeks) to achieve visual and anatomical improvements or stabilization.

No prospective, controlled, randomized clinical trials have compared the efficacy and safety of bevacizumab and ranibizumab in exudative AMD treatment in the Brazilian population, and no studies have evaluated fortnightly bevacizumab treatment. Accordingly, we aimed to evaluate and compare the clinical applications, efficacies, and safety of exudative AMD treatment with the administration of fortnightly bevacizumab, monthly bevacizumab, and monthly ranibizumab. We also analyzed the intraocular pressure (IOP) and changes in retinal pigment epithelial detachment (PED) over a year of treatment, and the vitreous statuses before and after 1 year of treatment.

\section{METHODS}

We conducted a parallel randomized clinical trial. We screened treatment-naive patients with exudative AMD and followed them in the Clinical Research and Retina Services of the Ophthalmology and Visual Sciences Department of the Paulista School of Medicine, Federal University of São Paulo, between June 2010 and February 2013. The institutional review board of the University of São Paulo (0345/10) approved this prospective study planned in accordance with the principles of the Declaration of Helsinki. We obtained informed consent forms from each patient after informing them of the procedures to be performed and their risks.

Eligibility criteria included the presence of choroidal neovascularization with sub-foveal impairment, central macular thickness (CMT) greater than $250 \mu \mathrm{m}$ as measured by spectral domain optical coherence tomography (SDOCT), and best-corrected visual acuity (BCVA) between 20/25 and 20/400, with an Early Treatment Diabetic Retinopathy Study (ETDRS) letter score between 20 and 80. Exclusion criteria included any sign of palpebral infection, allergy to fluorescein, ocular diseases that could present with low vision, fibrosis in more than $50 \%$ of the total neovascular lesion area, intraocular surgery in the past 2 months, previous intraocular treatment, significant media opacity, spherical equivalence of $-8.00 \mathrm{D}$ or more, or any uncontrolled systemic 
disease or condition that could interrupt the 1-year follow-up.

We understand that for a non-inferiority study, such as the CATT study, a sample size of more than 1,200 eyes would be necessary to have adequate statistical power to detect changes in visual acuity after 1 year. Unfortunately, such a trial would be impossible to conduct considering the situation in Brazil. Therefore, the purpose of our study was to calculate a minimum sample size that would provide adequate power $(80 \%)$ to detect at least one-line (5 letters) differences in visual acuity between the groups studied. We calculated that a sample size of 13 in each group would be feasible and adequate to detect such differences, considering a power of $80 \%$ and an alpha error of $5 \%$.

We divided patients into three groups, in a 1:1:1 ratio, according to the randomization table generated by the software Stata v.10 (College Station, TX, USA), using an allocation system in blocks of three. Investigators and examiners were blinded to the randomization results.

Patients in group 1 received monthly injections of $1.25 \mathrm{mg}(0.05 \mathrm{~mL})$ bevacizumab for 3 months; those in group 2 received fortnightly injections of $1.25 \mathrm{mg}(0.05 \mathrm{~mL})$ bevacizumab for 3 months; and those in group 3 received monthly injections of $0.5 \mathrm{mg}(0.05 \mathrm{~mL})$ ranibizumab for 3 months. After the first 3 months, patients from groups 1 and 3 were followed with monthly BCVA and SDOCT, and patients from group 2 with fortnightly evaluations. Patients in all groups were also followed with quarterly color fundus photographs (CFPs) and fluorescein angiographies (FAs). We repeated treatments in patients presenting any of the following signs: sub-retinal, retinal, or sub-RPE fluid; new or persistent hemorrhages; an increase in CMT of $50 \mu \mathrm{m}$ or more; leakage on FA; or loss of five or more ETDRS letters (1 or more lines). The treatment injections were administered in surgical rooms, following aseptic techniques and under local anesthesia. The medications were injected via the pars plana, $3.5 \mathrm{~mm}$ from the limbus in pseudophakic patients and $4.0 \mathrm{~mm}$ from it in phakic patients. We followed patients for 1 year, with monthly or fortnightly visits, according to their group.

The primary study outcomes were the ETDRS BCVA and CMT as measured by SDOCT (Spectralis, Heidelberg Engineering, Heidelberg, Germany). We also analyzed CFPs (Topcon Retinal Camera TRC-50X, Topcon Corporation, Tokyo, Japan) and FA (HRA2, Heidelberg Engineering) characteristics.
We collected data and presented them in contingency tables. In addition, we presented continuous variables as means and standard deviations, and categorical variables as frequencies and proportions. We used the non-parametric Mann-Whitney and Fisher exact tests to compare continuous and categorical variables, respectively, between groups. We performed longitudinal comparisons using the paired Wilcoxon test. We considered a $p<0.05$ as statistically significant. For all analyses, we used Stata v.10 software (College Station).

\section{RESULTS}

We included a total of 45 patients in the clinical trial and randomized them into three groups, with 15 patients in each. Figure 1 presents a flow diagram of the participant selection. Table 1 presents detailed characteristics of patients at the time of inclusion. The mean (standard deviation) age at baseline was 75.29 (8.03) years. After group stratification, the mean ages were 75.27 (8.77) years for patients in group 1, 75.60 (7.95) years for those in group 2, and 75.00 (7.89) years for those in group 3 . The age differences between the groups were not statistically significant $(\mathrm{p}=0.909)$.

We ended up including 21/45 (46.67\%) men and $24 / 45(53.33 \%)$ women $(p=0.929)$, with a predominance of Caucasian $(38 / 45,84.44 \% ; p=0.668)$ and African (35/45, 77.78\%; $p=0.550)$ descendants.

At baseline, 28/45 patients (62.22\%) had hypertension, 7 had type Il diabetes mellitus, 11 had cardiopathy, and 6 had had a thrombotic event, but were clinically controlled and stable at the time of inclusion in the study.

The mean (standard deviation) baseline BCVAs in $\operatorname{logMAR}$ were $0.656(0.326)$ for eyes in group $1,0.678$ $(0.324)$ for eyes in group 2, and $0.602(0.286)$ for eyes in group 3. After 1 year, the mean BCVAs in logMAR

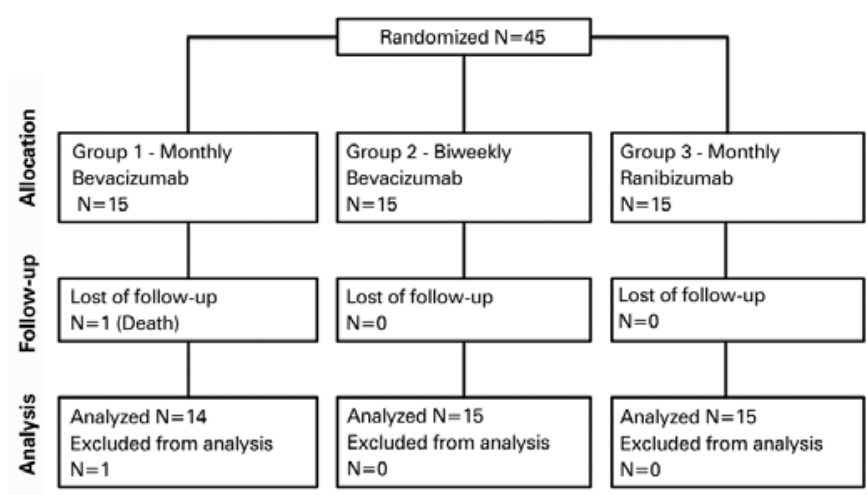

Figure 1. Flowchart of study participants. 
Table 1. Baseline data of patients included in the study

\begin{tabular}{|c|c|c|c|c|c|}
\hline $\begin{array}{l}\text { Characteristics } \\
\text { (N) }\end{array}$ & $\begin{array}{l}\text { Total } \\
(45)\end{array}$ & $\begin{array}{c}\text { Group } 1 \\
\text { (15) }\end{array}$ & $\begin{array}{c}\text { Group } 2 \\
(15)\end{array}$ & $\begin{array}{c}\text { Group } 3 \\
(15)\end{array}$ & $P$ value \\
\hline Age (years) & & & & & 0.909 \\
\hline Average & 75.29 & 75.27 & 75.60 & 75.00 & \\
\hline $\begin{array}{l}\text { Standard } \\
\text { deviation }\end{array}$ & 8.03 & 8.77 & 7.95 & 7.89 & \\
\hline Gender (\%) & & & & & 0.929 \\
\hline Male & $\begin{array}{l}46.67 \\
(21)\end{array}$ & $\begin{array}{l}53.33 \\
(8)\end{array}$ & $\begin{array}{l}40.00 \\
(6)\end{array}$ & $\begin{array}{l}46.67 \\
(7)\end{array}$ & \\
\hline Female & $\begin{array}{l}53.33 \\
(24)\end{array}$ & $\begin{array}{l}46.67 \\
(7)\end{array}$ & $\begin{array}{l}60.00 \\
(9)\end{array}$ & $\begin{array}{c}53.33 \\
(8)\end{array}$ & \\
\hline Race (\%) & & & & & 0.668 \\
\hline Caucasian & $\begin{array}{l}84.44 \\
(38)\end{array}$ & $\begin{array}{l}93.33 \\
(14)\end{array}$ & $\begin{array}{l}80.00 \\
(12)\end{array}$ & $\begin{array}{l}80.00 \\
(12)\end{array}$ & \\
\hline Other & $\begin{array}{l}15.56 \\
(7)\end{array}$ & $\begin{array}{l}6.67 \\
(1)\end{array}$ & $\begin{array}{l}20.00 \\
(3)\end{array}$ & $\begin{array}{l}20.00 \\
(3)\end{array}$ & \\
\hline Iris color (\%) & & & & & 0.550 \\
\hline Brown & $\begin{array}{l}77.78 \\
(35)\end{array}$ & $\begin{array}{l}66.67 \\
(10)\end{array}$ & $\begin{array}{l}86.67 \\
(13)\end{array}$ & $\begin{array}{l}80.00 \\
(12)\end{array}$ & \\
\hline Other & $\begin{array}{l}22.22 \\
(10)\end{array}$ & $\begin{array}{l}33.33 \\
(5)\end{array}$ & $\begin{array}{l}13.33 \\
(2)\end{array}$ & $\begin{array}{l}20.00 \\
(3)\end{array}$ & \\
\hline Study eye (\%) & & & & & 0.388 \\
\hline Right & $\begin{array}{l}60.00 \\
(27)\end{array}$ & $\begin{array}{l}73.33 \\
(11)\end{array}$ & $\begin{array}{l}60.00 \\
(9)\end{array}$ & $\begin{array}{l}46.67 \\
(7)\end{array}$ & \\
\hline Left & $\begin{array}{l}40.00 \\
(18)\end{array}$ & $\begin{array}{c}26.67 \\
(4)\end{array}$ & $\begin{array}{l}40.00 \\
(6)\end{array}$ & $\begin{array}{l}53.33 \\
(8)\end{array}$ & \\
\hline BCVA (logMAR) & & & & & 0.817 \\
\hline Average & 0.645 & 0.656 & 0.678 & 0.602 & \\
\hline $\begin{array}{l}\text { Standard } \\
\text { deviation }\end{array}$ & 0.307 & 0.326 & 0.324 & 0.286 & \\
\hline $\mathrm{CMT}(\mu \mathrm{m})$ & & & & & 0.793 \\
\hline Average & 515.10 & 490.93 & 523.83 & 533.50 & \\
\hline $\begin{array}{l}\text { Standard } \\
\text { deviation }\end{array}$ & 153.81 & 133.45 & 177.40 & 160.87 & \\
\hline
\end{tabular}

$\mathrm{N}=$ number of patients; $\mathrm{BCVA}=$ best-corrected visual acuity; $\log \mathrm{MAR}=$ logarithm of the minimum angle of resolution; $\mathrm{CMT}=$ central macular thickness. were $0.511(0.404)$ for eyes in group $1(\mathrm{p}=0.059), 0.410$ (0.248) for eyes in group $2(p=0.009)$, and $0.356(0.241)$ for eyes in group $3(p=0.002)$. By the end of the treatment, we found mean gains of 5.93, 13.4, and 12.33 ETDRS letters in the eyes of patients in groups 1,2 , and 3, respectively (Figure 2).

After the follow-ups, $38.6 \%$ of all patients included in the study had gained 15 or more vision letters, $21.4 \%$ of eyes in group 1 and $46.7 \%$ of eyes in groups 2 and 3 , with no statistically significant difference between the three groups $(p=0.277)$.

The mean (standard deviation) baseline CMTs were 515.10 (153.8) $\mu \mathrm{m}$ for all groups together, 490.93 (133.5) $\mu \mathrm{m}$ for eyes in group 1, 523.83 (177.4) $\mu \mathrm{m}$ for eyes in group 2 , and 533.5 (160.8) $\mu \mathrm{m}$ for eyes in group 3 $(p=0.7928)$. By the end of the follow-ups, the mean (standard deviation) CMTs decreased to 343.61 (113.4), 324.21 (113.6), and 317.5 (74.2) $\mu \mathrm{m}$ for eyes in groups 1,2 , and 3, respectively (Figure 3). The CMT decreases (pre- vs. post-treatment) were statistically significant in all three groups $(p=0.003, p=0.002$, and $p=0.001$, for eyes in groups 1,2 , and 3 , respectively).

The mean (standard deviation) numbers of intravitreal injections given during the first year of follow-up were 10.47 (4.19), 17.00 (6.68), and 10.6 (2.56) in groups 1,2 , and 3 , respectively.

Figures 4-6 present three representative clinical cases with good treatment responses. Figure 4 presents a patient from group 1 with a large PED showing excellent response since the beginning of the treatment. Figure 5 shows the first 3 months of follow-up for a patient from group 2, who was treated every 2 weeks with fixed injections in all first six study visits and was then followed

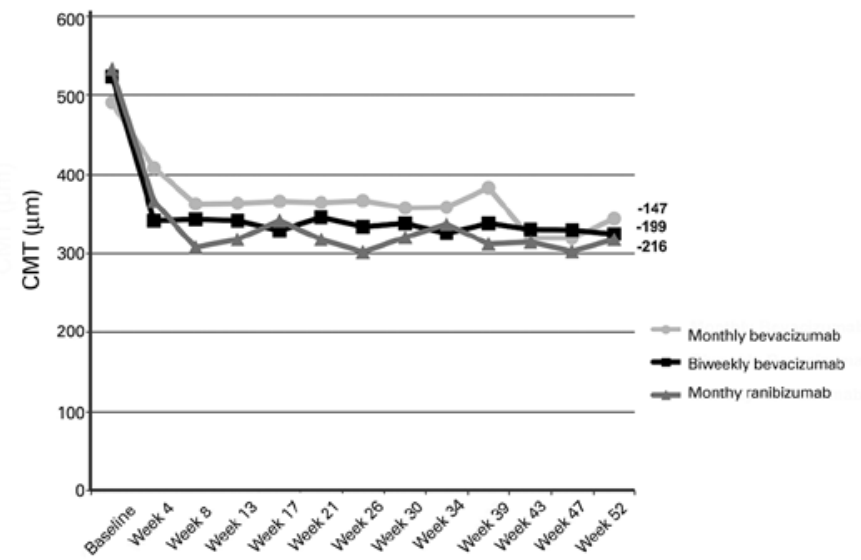

Figure 3. Central macular thickness (CMT) changes $(\mu \mathrm{m})$ over 12 months.
Figure 2. Best-corrected visual acuity (BCVA) changes in Early Treatment

Diabetic Retinopathy Study (ETDRS) letters over 12 months.

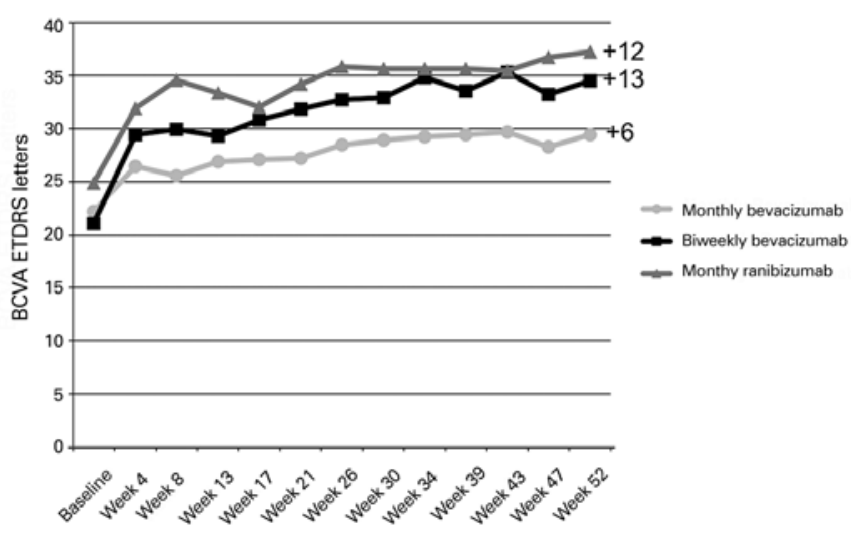


with retreatments as needed. Despite the case severity, the patient progressed with a good treatment response. Figure 6 presents a representative case from group 3.

We also performed sub-analyses of other variables, such as IOP, posterior vitreous detachment (PVD), and resolution of PED, but found no statistically significant differences between the groups. The mean (standard deviation) baseline IOP values were 12.43 (4.3), 12.6 (3.3), and 13.4 (2.8) $\mathrm{mmHg}$ in the eyes of groups 1 , 2 , and 3 , respectively. By the end of the first year of follow-up, the mean IOP values were 13.5 (3.4), 13.1 (3.0), and 13.3 (3.2) $\mathrm{mmHg}$ in the eyes of groups 1, 2, and 3 , respectively (Table 2 ).

We classified PVDs based on the SDOCT findings as partial, total, absent (attached vitreous), or not visualized. At baseline, the percentages of patients with total PVD were $6.67 \%$ in group $1,13.33 \%$ in group 2 , and $7.14 \%$ in group 3 . However, at baseline, $33.33 \%$ of eyes in group 1, 20.00\% in group 2, and $50.00 \%$ in group 3 had partial PVDs. By the end of the follow-ups ( 1 year after the initial treatment) $23.08 \%$ of eyes in group 1 ,
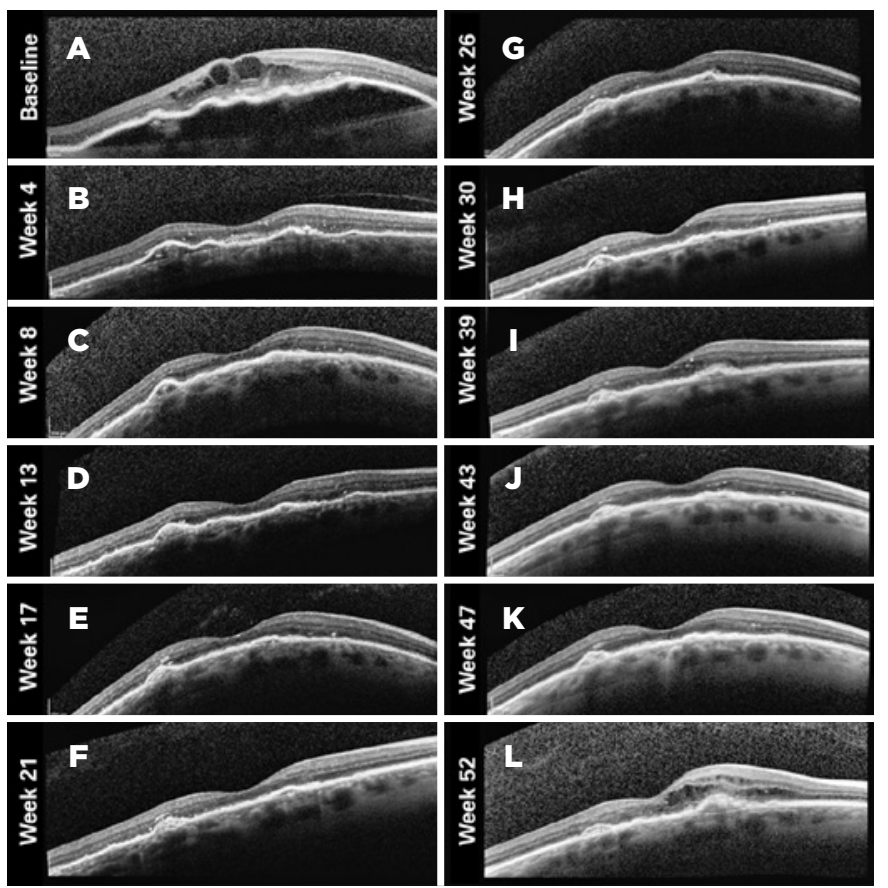

Figure 4. Representative study patient number 4 from group 1: a 76 -year-old man who underwent a bevacizumab injection at baseline and at weeks 4 , 8, 39, and 52 (a total of 5 injections over a year). (A) Best-corrected visual acuity (BCVA) 57 Early Treatment Diabetic Retinopathy Study (ETDRS) letters, first intravitreal injection (IVT); (B) BCVA 64 letters, second IVT; (C) BCVA 64 letters, third IVT; (D-H) BCVA 62 letters, observation; (I) BCVA 62 letters, retinal fluid recurrence, fourth IVT; (J and K) BCVA 66 letters, observation; (L) BCVA 61 letters, retinal fluid recurrence at the last study visit, fifth IVT.
$28.57 \%$ in group 2 , and $28.57 \%$ in group 3 displayed total PVD, and $30.77 \%, 7.14 \%$, and $28.57 \%$ showed partial PVD, respectively. These differences were not statistically significant within each group, or between groups $(p=0.684)$ (Table 2).

At baseline, $86.67 \%$ of patients in group $1,73.33 \%$ in group 2, and $85.71 \%$ in group 3 presented PEDs. By the end of the 12 months of follow-up, $61.54 \%$ of patients in group $1,42.86 \%$ in group 2 , and $71.43 \%$ in group 3 showed PEDs. Thus, the frequency of PED decreased in all groups, but the differences were not statistically significant both within each group (pre- vs. post-treatment; $p=0.250$ for group $1, p=0.125$ for group 2 , and $p=0.625$ for group 3$)$ and between groups $(p=0.325)$ after 1 year (Table 2).
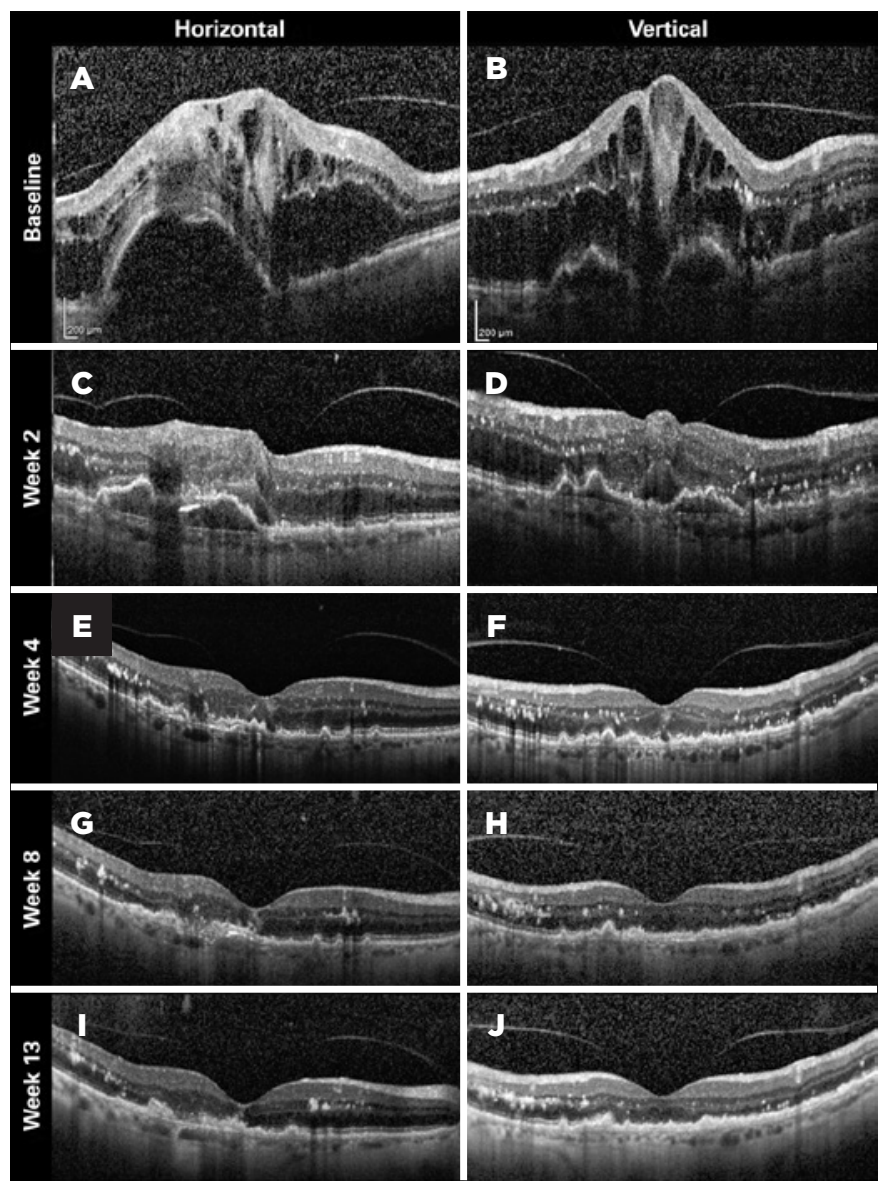

Figure 5. Representative study patient number 6 from group 2: a 79-year-old woman, with follow-ups every 2 weeks, she underwent a total of 14 bevacizumab intravitreal injections (IVTs) over a year. (A and B) Baseline, best-corrected visual acuity (BCVA) 27 Early Treatment Diabetic Retinopathy Study (ETDRS) letters, first IVT; (C and D) week 2, BCVA 53 letters, second IVT; (E and F) week 4, BCVA 54 letters, third IVT; (G and H) week 8, BCVA 58 letters, fifth IVT; (I and J) week 13 (15 days after the sixth IVT), BCVA 59 letters, observation. 

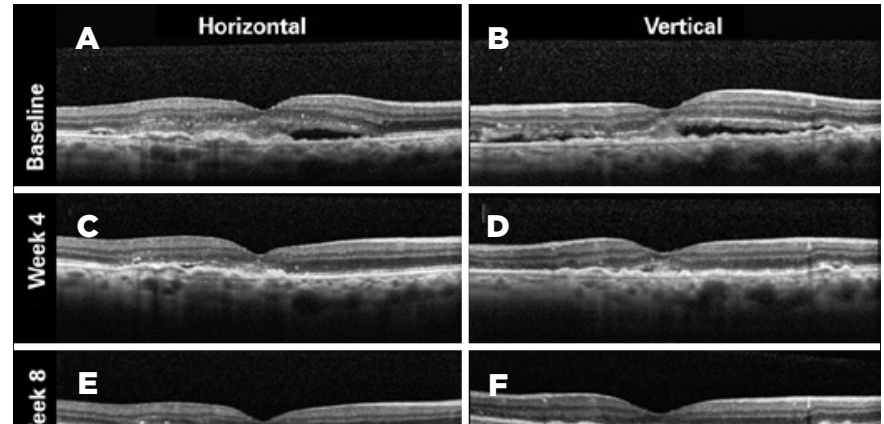

ב
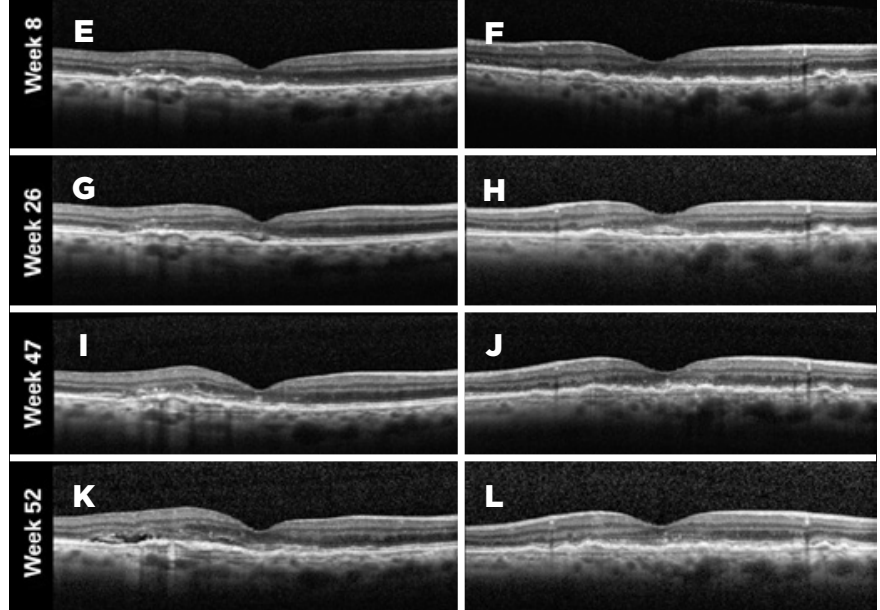

Figure 6. Representative study patient number 37 from group 3: a 70-year-old man, with monthly follow-ups with as-needed treatment with ranibizumab. (A and B) Baseline, best-corrected visual acuity (BCVA) 75 Early Treatment Diabetic Retinopathy Study (ETDRS) letters, first intravitreal injection (IVT); (C and D) week 4, BCVA 84 letters, second IVT; ( $E$ and F) week 8, BCVA 83 letters, third IVT; (G and H) week 26, BCVA 85 letters, seventh IVT; (I and J) week 47, BCVA 85 letters, observation; ( $\mathrm{K}$ and $\mathrm{L}$ ) week 52, last study visit, BCVA 86 letters, twelfth IVT.

Table 2. Sub-analyses of intraocular pressure, posterior vitreous detachment, and retinal pigmented epithelial detachment

\begin{tabular}{lcccc}
\hline & Group 1 & Group 2 & Group 3 & p value \\
\hline IOP (mmHg) & & & & \\
Baseline & 12.43 & 12.60 & 13.40 & \\
Week 52 & 13.50 & 13.10 & 13.30 & \\
Total PVD (\%) & & & & $\mathbf{0 . 6 8 4}$ \\
Baseline & 6.67 & 13.33 & 7.14 & \\
Week 52 & 23.08 & 28.57 & 28.57 & \\
PED (\%) & & & & $\mathbf{0 . 3 2 5}$ \\
Baseline & 86.67 & 73.33 & 85.71 & \\
Week 52 & 61.54 & 42.86 & 71.43 & \\
\hline
\end{tabular}

$\mathrm{IOP}=$ intraocular pressure $\mathrm{PVD}=$ posterior vitreous detachment; $\mathrm{PED}=$ retinal pigmented epithelial detachment.

Mild conjunctival hyperemia, subconjunctival hemorrhage at the injection site, and transient floaters right after the drug was injected were observed with similar frequency in all the three groups. No cases of vitreous hemorrhage, retinal detachment, severe uveitis, or endophthalmitis were observed in any of the patients.
The occurrence of systemic adverse events was low, with only one patient in group 1 and one in group 2 experiencing episodes of transient ischemic attack approximately 1 week after two of the injections, but the adverse events did not recur after the subsequent injections in either patient. One patient in group 1 died due to a pulmonary infection. One patient from group 1 displayed epistaxis and massive subconjunctival hemorrhage after approximately 1 week of the fifth injection. We found no discrepancies in the efficacy or safety of the treatments among the study patients.

\section{DISCUSSION}

Due to its low cost, off-label bevacizumab use has increased significantly during the last 10 years since its first use, mainly after evidence of its non-inferiority compared to ranibizumab by the CATT and IVAN studies was published $^{(18,19)}$.

Our results were consistent with those in the literature, and show that monthly or fortnightly bevacizumab, or monthly ranibizumab are all effective for exudative AMD treatment, considering the vision improvement and CMT reduction in our Brazilian study population.

We observed a tendency toward greater vision improvements in the monthly ranibizumab and fortnightly bevacizumab groups compared to those in the monthly bevacizumab group. But we cannot identify the exact reason for this finding that might represent a true better response in groups 2 and 3 (our small sample size did not allow us to confirm this). However, another possibility is that patients included in the monthly bevacizumab group had a more severe baseline disease, despite the randomization, and we could not rule this out for the same reason. To us, this hypothesis seems more plausible, considering the findings in the literature regarding vision gains.

The mean gain of letters in the monthly bevacizumab group (as-needed treatment, with monthly follow-up) was similar to that with discontinuous treatment in the CATT study, with gains of 6.0 letters in our study and 5.9 letters in the CATT study ${ }^{(16)}$. On the other hand, the patients receiving monthly ranibizumab had a mean gain of 13 letters, superior to the gains in the literature (6.8 letters in the discontinuous ranibizumab group in the CATT study and 11.3 letters in the monthly treatment group in the ANCHOR study) $)^{(8,16,23,24)}$.

Our study included a group that underwent fortnightly bevacizumab treatment to evaluate a possible 
benefit for less responsive cases (e.g., patients with PED or initial fibrosis). However, the vision improvement in this group was comparable to that in the monthly ranibizumab treatment group (12 vs. 13 letters, respectively). To date, only case reports have evaluated this type of treatment (no prospective studies); therefore, we cannot compare our results to those in the literature ${ }^{(15)}$.

We found no statistically significant differences between groups regarding the sub-analyses of fibrosis onset and PED resolution. PED evaluation showed a tendency for greater resolution in the group treated with fortnightly injections than in groups treated with monthly injections, but without statistical significance. Although no clinical studies with fortnightly use of anti-VEGF besides the published case reports exist, our results suggest that more frequent dosing may improve PED resolution, but this needs to be confirmed in larger sample studies, especially for patients with poor response to monthly injections ${ }^{(15)}$.

All groups showed a tendency toward total PVD increases over 12 months of follow-up. However, we observed no statistically significant differences in the vitreous statuses either within each group or between groups. We had thought that the patients receiving fortnightly doses would probably show a greater tendency toward PVD, due to the repeated injections, regardless of the medication. But we cannot confirm or rule out the possibility due to the small sample size and because group 2 already had more patients with total PVD at baseline. Studies with a bigger sample size should evaluate PVD changes with more frequent injection protocols.

When considering patient adherence to treatment, adverse effects, and follow-up difficulties, the treatment with fortnightly injections proved to be feasible both for patients and staff for the period of 1 year evaluated in our study.

Regarding safety, we found no significant differences between groups, and had a low rate of severe ocular or systemic adverse events in all three groups.

Although the intensive treatment strategy in our study carries with it an increased risk of complications secondary to the intravitreal injection itself (retinal detachment, endophthalmitis, and vitreous hemorrhage, among others), we found no serious local complications. However, studies have associated the incidence of geographic atrophy with the number of anti-VEGF injections ${ }^{(18)}$; therefore, physicians and patients should be aware of this possibility when deciding on this type of more frequent injection protocol. The attending phy- sician should ensure adequate aseptic care and correct intravitreal injection technique. Another important matter regarding the intensive treatment protocol is the increase in the number of injections, and thus the treatment cost. All these factors make this a choice restricted to selected cases.

A major limitation of this study was the small number of patients included in each group, as well as the limitations inherent to single-center studies. We could not recruit more patients due to the limited number of injections obtained for the study. A large multicenter study would require involving centers in different regions of Brazil to obtain more conclusive results. However, despite the limitations, this is the first study in Brazil comparing ranibizumab and bevacizumab, and including a treatment group with fortnightly doses.

In all, the follow-ups every 2 weeks proved feasible, in terms of adherence by patients, and technical conditions and treatment safety. We found no significant differences in efficacy or safety between bevacizumab and ranibizumab treatments. We found no IOP changes within each group or between groups during the study period. We observed a greater tendency toward PED resolution with the fortnightly treatment, but without statistical significance. We found no statistically significant variations in vitreous statuses.

Based on the data presented, we recommend fortnightly bevacizumab for a short period of time in patients with poor response to monthly treatment.

\section{REFERENCES}

1. Resnikoff S, Pascolini D, Etya'ale D, Kocur l. Global data on visual impairment in the year 2002. Bull World Health Organ. 2004; 82(11):844-51.

2. Bird AC, Bressler NM, Bressler SB, Chisholm IH, Coscas G, Davis $M D$, et al. An international classification and grading system for age-related maculopathy and age-related macular degeneration. The International ARM Epidemiological Study Group. Surv Ophthalmol. 1995;39(5):367-74.

3. Friedman DS, O'Colmain BJ, Muñoz B, Tomany SC, McCarty C, de Jong PT, Nemesure B, Mitchell P, Kempen J; Eye Diseases Prevalence Research Group. Prevalence of age-related macular degeneration in the United States. Arch Ophthalmol. 2004;122(4):564-72.

4. Klein R, Peto T, Bird A, Vannewkirk MR. The epidemiology of age-related macular degeneration. Am J Ophthalmol. 2004;137(3): 486-95.

5. Zarbin MA. Current concepts in the pathogenesis of age-related macular degeneration. Arch Ophthalmol. 2004;122(4):598-614.

6. Ferrara N. Vascular endothelial growth factor: basic science and clinical progress. Endocr Rev. 2004;25(4):581-611.

7. Ferrara N, Damico L, Shams N, Lowman H, Kim R. Development of ranibizumab, an anti-vascular endothelial growth factor antigen binding fragment, as therapy for neovascular age-related macu- 
lar degeneration. Retina. 2006;26(8):859-70. doi:10.1097/01. iae.0000242842.14624.e7

8. Rosenfeld PJ, Brown DM, Heier JS, Boyer DS, Kaiser PK, Chung CY, Kim RY, MARINA Study Group. Ranibizumab for neovascular age-related macular degeneration. N Engl J Med. 2006 Oct 5;355(14):1419-31. Comment in: N Eng J Med. 2006;355(14):1409-12. N Engl J Med. 2007;356(7):748-9. N Engl J Med. 2006;355(14):1495-5. N Engl J Med. 2007;356(7):747-8. doi:10.1056/NEJMc063011

9. Hurley SF, Matthews JP, Guymer RH. Cost-effectiveness of ranibizumab for neovascular age-related macular degeneration. Cost Eff Resour Alloc. 2008;6:12. doi: 10.1186/1478-7547-6-12.

10. Rosenfeld PJ, Moshfeghi AA, Puliafito CA. Optical coherence tomography findings after an intravitreal injection of bevacizumab (avastin) for neovascular age-related macular degeneration. Ophthalmic Surg Lasers Imaging. 2005;36(4):331-5. Comment in: Ophthalmic Surg Lasers Imaging. 2005;36(4):270-1.

11. Avery RL, Pieramici DJ, Rabena MD, Castellarin AA, Nasir MA, Giust M). Intravitreal bevacizumab (Avastin) for neovascular age-related macular degeneration. Ophthalmology. 2006;113(3):363-372. e365.

12. Rich RM, Rosenfeld PJ, Puliafito CA, Dubovy SR, Davis JL, Flynn HW Jr., et al. Short-term safety and efficacy of intravitreal bevacizumab (Avastin) for neovascular age-related macular degeneration. Retina. 2006;26(5):495-511.

13. Bashshur ZF, Bazarbachi A, Schakal A, Haddad ZA, El Haibi CP, Noureddin BN. Intravitreal bevacizumab for the management of choroidal neovascularization in age-related macular degeneration. Am J Ophthalmol. 2006;142(1):1-9.

14. Tufail A, Patel PJ, Egan C, Hykin P, da Cruz L, Gregor Z, Dowler J, Majid MA, Bailey C, Mohamed Q, Johnston R, Bunce C, Xing W; $\mathrm{ABC}$ Trial Investigators. Bevacizumab for neovascular age related macular degeneration (ABC Trial): multicentre randomised double masked study. BMJ. 2010;340:c2459. doi:10.1136/bmj.c2459.

15. Stewart MW, Rosenfeld PJ, Penha FM, Wang F, Yehoshua Z, Bueno-Lopez E, et al. Pharmacokinetic rationale for dosing every 2 weeks versus 4 weeks with intravitreal ranibizumab, bevacizumab, and aflibercept (vascular endothelial growth factor Trap-eye). Retina. 2012;32(3):434-57.

16. CATT Research Group, Martin DF, Maguire MG, Ying GS, Grunwald JE, Fine SL, Jaffe GJ. Ranibizumab and bevacizumab for neovascular age-related macular degeneration. N Engl ) Med. 2011;364(20):1897-908. doi:10.1056/NEJMoa1102673. Comment in: N Engl J Med. 2011;364(20):1966-7. N Engl J Med. 2011;365(23):2238. Clin Exp Ophthalmol. 2011;39(7):718-20. JAMA. 2014;311(15):1491-2. N Engl J Med. 2011;365(23):2237.

17. IVAN Study Investigators, Chakravarthy U, Harding SP, Rogers CA, Downes SM, Lotery AJ, Wordsworth S, Reeves BC.
Ranibizumab versus bevacizumab to treat neovascular age-related macular degeneration: one-year findings from the IVAN randomized trial. Ophthalmology. 2012 Jul;119(7):1399-411. doi: 10.1016/j.ophtha.2012.04.015. Erratum in: Ophthalmology. 2012; 119(8):1508. Ophthalmology. 2013;120(9):1719.

18. Comparison of Age-related Macular Degeneration Treatments Trials (CATT) Research Group, Martin DF, Maguire MG, Fine SL, Ying GS, Jaffe G), Grunwald JE, Toth C, Redford M, Ferris FL 3rd. Ranibizumab and bevacizumab for treatment of neovascular age-related macular degeneration: two-year results. Ophthalmology. 2012 Jul;119(7):1388-98. doi: 10.1016/j.ophtha.2012.03.053. Comment in: J Comp Eff Res. 2012;1(6):485-8. JAMA Ophthalmol. 2015; 133(3):363-4. JAMA Ophthalmol. 2015;133(6):726.

19. Chakravarthy U, Harding SP, Rogers CA, Downes SM, Lotery AJ, Culliford LA, Reeves BC; IVAN Study Investigators. Alternative treatments to inhibit VEGF in age-related choroidal neovascularization: 2-year findings of the IVAN randomised controlled trial. Lancet. 2013;382(9900):1258-67. Comment in: Lancet. 2013;382(9900):1230-2.

20. Subramanian ML, Abedi G, Ness S, Ahmed E, Fenberg M, Daly MK, et al. Bevacizumab vs ranibizumab for age-related macular degeneration: 1-year outcomes of a prospective, double-masked randomised clinical trial. Eye (Lond). 2010;24(11):1708-15. doi: 10.1038/eye.2010.147. Comment in: Eye (Lond). 2011;25(6):820.

21. Valmaggia $C$, Haueter $I$, Kloos $P$, Lang $C$, Niederberger $H$. The treatment of choroidal neovascularizations in age-related macular degeneration using either Avastin or Lucentis. Klin Monbl Augenheilkd. 2009;226(4):294-8.

22. Krebs I, Schmetterer L, Boltz A, Told R, Vécsei-Marlovits V, Egger S, Schönherr U, Haas A, Ansari-Shahrezaei S, Binder S; MANTA Research Group. A randomised double-masked trial comparing the visual outcome after treatment with ranibizumab or bevacizumab in patients with neovascular age-related macular degeneration. Br J Ophthalmol. 2013;97(3):266-71. doi:10.1136/ bjophthalmol-2012-302391. Comment in: Br J Ophthalmol. 2013; 97(3):248-50.

23. Brown DM, Kaiser PK, Michels M, Soubrane G, Heier JS, Kim RY, Sy JP, Schneider S; ANCHOR Study Group. Ranibizumab versus verteporfin for neovascular age-related macular degeneration. $\mathrm{N}$ Engl J Med. 2006;355(14):1432-44. Comment in: N Engl J Med. 2006;355(14):1409-12. N Engl J Med. 2006355(14):1493-5. N Engl J Med. 2007;356(7):747-8.

24. Regillo CD, Brown DM, Abraham P, Yue H, lanchulev T, Schneider $\mathrm{S}$, et al. Randomized, double-masked, sham-controlled trial of ranibizumab for neovascular age-related macular degeneration: PIER Study year 1. Am J Ophthalmol. 2008;145(2):239-48. 